\title{
Kadın Voleybolculara Uygulanan Core ve Düzeltici Egzersizlerin Fonksiyonel Hareket Taraması Test Skorlarına Etkisi
}

\author{
Emre ALTUNDAĞ'1 (iD, Hasan AKA ${ }^{2}$ (D) , Zait Burak AKTUĞ² \\ Cengiz AKARÇEŞME ${ }^{3}$ (D) , Çağlar SOYLU4 \\ 1 Gazi Üniversitesi, Sağlık Bilimleri Enstitüsü, ANKARA \\ 2 Niğde Ömer Halisdemir Üniversitesi, Spor Bilimleri Fakültesi, NiĞDE \\ ${ }^{3}$ Gazi Üniversitesi, Spor Bilimleri Fakültesi, ANKARA \\ ${ }^{4}$ Sağlık Bilimleri Üniversitesi, Gülhane Sağlık Bilimleri Fakültesi, ANKARA
}

Araştırma Makalesi

DOI: $10.53434 /$ gbesbd.932956

Öz

Bu çalışmanın amacı kadın voleybolculara uygulanan core ve düzeltici egzersizlerin, Fonksiyonel Hareket Taraması (FMS) test skorlarına etkisinin incelenmesidir. Çalışmaya 13 kadın voleybolcu (yaş= 27,53 $\pm 5,12$ yll) gönüllü olarak katılmıştır. Katılımcıların fonksiyonel hareketleri FMS test kiti ile belirlenmiştir. Voleybolculara haftada 3 gün olmak üzere 8 hafta boyunca core ve düzeltici egzersiz programı uygulanmıştır. Voleybolcuların FMS alt testleri ve FMS toplam puanları ile ön test ve uygulanan egzersiz programı sonrası son test puanlarının istatistiksel farkları Wilcoxon Isşaretli Siralar Testi ile belirlenmiştir. Yapılan istatistiksel analiz sonucunda voleybolcuların omuz hareketliliği, gövde rotasyon dengesi ve FMS toplam puanları son testte istatistiksel olarak anlamlı fark gösterdiği, diğer alt testlerden alınan puanların ise anlamlı fark olmamasına rağmen geliştiği belirlenmiştir. Uygulanan core ve düzeltici egzersizlerin voleybolcularda fonksiyonel hareket kalıplarını geliştirdiği ve yaralanma potansiyelini azalttı̆̆ bulunmuştur. Voleybolda sporcuların yaralanma risklerini azaltmak ve fonksiyonel hareket kalıplarını geliştirmek için antrenman programlarına core ve düzeltici egzersizlerin de eklenmesi önerilebilir.

Anahtar Kelimeler: Voleybol, Core egzersizler, Düzeltici egzersizler, FMS 


\title{
The Effects of Core and Corrective Exercises Applied to Female Volleyball Players on Functional Movement Screen Test Results
}

\begin{abstract}
The aim of this study is to examine the effect of core and corrective exercises on Functional Movement Screen (FMS) test results. Thirteen female volleyball players (age $=27.53 \pm 5.12$ ) participated in the study voluntarily. The functional movements of the participants were determined with the FMS test kit. Core and corrective exercise programs were applied to volleyball players for 8 weeks, 3 days a week. The statistical differences between the volleyball players' FMS subtests and FMS total scores and the pre-test and post-test scores after the exercise program were determined by the Wilcoxon Signed-Ranks Test. As a result of the statistical analysis, it was determined that the shoulder mobility, rotary stability and FMS total scores of the volleyball players showed a statistically significant difference in the posttest, and the scores from the other subtests improved although there was no significant difference. It has been found that applied core and corrective exercises improve functional movement patterns and reduce injury potential in volleyball players. In volleyball, it may be recommended to integrate core and corrective exercises to training programs to reduce the risk of injuries and improve functional movement patterns.
\end{abstract}

Key words: Volleyball, Core exercises, Corrective exercises, FMS

\section{Giriş}

Voleybolda temel fiziksel becerilerin istenilen seviyede uygulanabilmesinde genel kuvvetin; hücum organizasyonlarında ise çabuk kuvvet ve kuvvette devamlılık gibi koordinatif yeteneklerin yeterli düzeyde olması gerekmektedir (Aslan, Koç ve Karakullukçu, 2015). Bu nedenle çalıştırıcılar sporcuların kuvvet becerilerini farklı yöntemler kullanarak geliştirmeyi amaçlar.

Sporcularda kuvvet gelişimini sağlayan yöntemlerden birisi olan core egzersizler, bireyin kendi vücut ağırlığını kullanarak lumbopelvik kasları ve omurgayı dengede tutan derin kasların gelişimini sağlar (Atan, 2013). Core bölgesi, insan vücudunun ağırlık merkezi ile birlikte bel, pelvis, kalça ve karın kısımlarını kapsayan farklı kasların bulunduğu bölgenin ismidir (Behm, Drinkwater, Willardson ve Cowley 2010; Samson, 2005). Anatomik açıdan core bölgesi, gövde bölgesinin iskelet sistemi (göğüs kafesi, omurga, pelvis, omuz kemeri) ve yumuşak dokular (kıkırdak ve bağ dokular) ile bağlantılı vücudun stabilitesini sağlayan, aktif hareketlerde rol alan kasların bütünüdür (Axel, 2013; Behm, Drinkwater, Willardson ve Cowley 2010; Fig, 2005; Samson, Sandrey ve Hetrick, 2007; Hibbs, Thompson, French, Wrigley ve Spears, 2008). Core kaslarına yönelik olarak uygulanan direnç ve dayanıklılık antrenmanları sonucunda kol ve bacak hareketleri sportif performansta daha etkin bir rol oynar. Core kaslarındaki zayıflık veya dengesizlik ise spor yaralanmalarına yol açabilir (Willardson, 2014). 
Sporda meydana gelebilecek yaralanmaların tahmin edilerek önlem alınması, sporcuların performans verimliliği açısından hayati derecede önemlidir (Kiesel, Plisky ve Voight 2007). Fonksiyonel Hareket Taraması (FMS) testi, sporcularda oluşabilecek yaralanmaların tahmin edilmesinde bir laboratuvara ya da pahalı ekipmanlara ihtiyaç duyulmadan saha içerisinde hızlı ve kolay bir şekilde uygulanabilen bir tarama aracıdır. FMS test bataryası sporculardaki temel hareket kalıplarının basit yöntemlerle analizini sağlar (Kraus, Schütz, Taylor ve Doyscher, 2014). Bu test ile gözlemsel değerlendirmeler yapılmasına rağmen testin sonuçları güvenilirdir (Minick ve diğerleri, 2010; Onate ve diğerleri, 2012). FMS ile yapılan taramalarda, fonksiyonel hareketlerdeki kısıtlılık, asimetri ve işlevsizlikler belirlenir (Chorba ve diğerleri, 2010).

Literatürde FMS test bataryası ile fonksiyonel hareket paternlerindeki güçlü ve zayıf yönlerin tanımlandığı ve yaralanma risklerinin belirlendiği kabul edilir (Cook, Burton ve Hoogenboom, 2006a; Cook, Burton, Hoogenboom ve Voight, 2014). Sporcularda fonksiyonel hareket kalıplarındaki kısıtlılık nedeniyle oluşan asimetri ve işlevsizlikler sonucunda performans kayıpları ve yaralanmalar olabileceği belirtilmektedir (Kiesel, Plisky ve Voight, 2007). Fonksiyonel hareketleri değerlendiren birçok çalışmada FMS skorlarındaki düşük puanların ve asimetrilerin, sporcularda yaralanma olasılıklarını artırdığı bulunmuştur (Chorba ve diğerleri, 2010; Kiesel, Plisky ve Voight, 2007; Kiesel, Plisky ve Kersey, 2008).

Sporcularda fonksiyonel hareket kalıplarının geliştirilmesi, sporcuların verimliliğini artırıcı bir unsur olarak düşünülebilir. Son yıllarda sporcularda fonksiyonel hareket kalıpları, düzeltici egzersizler kullanılarak geliştirilmeye başlanmıştır (Mokha, Sprague ve Gatens, 2016). Voleybolda smaç ve servis gibi temel teknikler, dominant tarafla uygulandığı için sporcuların fonksiyonel hareket kalıplarında asimetriler ve işlevsel kayıplar olabilmektedir. $\mathrm{Bu}$ nedenle voleybolculara uygulanacak core ve düzeltici egzersizlerin hareket paternlerini geliştireceği, asimetrileri önleyebileceği düşünülmektedir.

Literatürde kadın voleybolculara uygulanan düzeltici egzersizlerin FMS test skorlarına etkisini inceleyen sınırlı sayıda çalışma bulunmaktadır (Aktuğ, Aka, Akarçeşme, Çelebi, Altundağ, 2019). Voleybolculara uygulanan core ve düzeltici egzersizlerin, FMS test skorlarına etkisini inceleyen bir çalışma ise bulunmamaktadır. Bu bağlamda bu çalıșmanın amacı, voleybolculara uygulanan core ve düzeltici egzersizlerin FMS test skorlarına etkisinin incelenmesidir.

\section{Yöntem}

Çalışmaya Kalecik Belediyespor Kadın Voleybol Takımı'ndan 13 voleybolcu (yaş= 27,53 \pm 5,12 yıl) katılmıștır. Katılımcıların son 6 ay içerisinde herhangi bir yaralanmaya maruz kalmaması, en az 3 yıldır lisanslı olarak voleybol oynaması, uygulanacak testlere ve egzersizlere aşina olması çalışmaya dahil edilme kriterleri olarak kabul edilmiştir. 
Testler müsabaka döneminde voleybolcuların izin yaptıkları, menstrüasyon döneminde olmadıkları ve son 24 saat içerisinde herhangi bir sportif aktiviteye katılmadıkları zamanda uygulanmıștır. Çalışmaya gönüllü olarak katılmayı kabul eden sporcuların sözlü onamları alınmıştır.

Helsinki Deklerasyonu prensipleri'ne uygun olarak uygulanmış çalışmanın etik kurul onayı, Ankara Yıldırım Beyazıt Üniversitesi Etik Kurulu'nun 16.02.2021 tarih ve 59 nolu toplantısında 2021-59 araştırma kodu ile alınmıştır.

\section{Veri Toplama Araçları}

\section{Antropometrik Ölçümler}

Voleybolcuların boy uzunluğu ve vücut ağırlığı boy ölçerli baskül (Seca 700; Seca GmbH \& Co. KG., Hamburg, Germany) kullanılarak çıplak ayak ile üzerlerinde şort ve tişört varken belirlenmiştir.

\section{Fonksiyonel Hareket Tarama (FMS) Testi}

Voleybolculara uygulanan yeni tip FMS testi, Gray Cook tarafından geliştirilen FMS kiti (Functional Movement Systems Inc., Virginia, USA) kullanılarak 2. Seviye sertifikası olan bir uzman tarafından yapılmıștır. FMS sporcularda kas dengesizliği, dominant ve dominant olmayan tarafta fonksiyonel performansları ve asimetriyi değerlendiren bir analiz sistemidir.

Bu test Gray Cook, Burton ve Hoogenboom (2006a) tarafindan belirlenen 7 temel parametreden (derin çömelme, yüksek adımlama, tek çizgide hamle, omuz mobilitesi, aktif düz bacak kaldırma, gövde stabilitesi şınavı, rotasyon stabilitesi) oluşur. Ancak FMS kurucuları tarafından 7 temel hareketten birisi olan rotasyon stabilitesi alt parametresinde çoğu kişinin kolay bir şekilde 2 puan alması ve testin güvenirliliğini azaltmasından dolayı hareketin daha zor hale getirildiği bir güncelleme yapılmıştır (FMS, 2020).

$\mathrm{Bu}$ çalışmada sporculara yapılan mevcut güncellemelerin olduğu yeni tip FMS testi uygulanmıştır. FMS kriterlerine göre sporculara her test için 0-3 arası bir puan alırken 7 testin beşine (derin çökme, engel adımı, ileriye düz çökme, omuz hareketliliği, aktif düz bacak kaldırma, şınav, gövde rotasyon dengesi) vücudun sol ve sağ tarafları için bağımsız puanlar verilmiştir. Toplam skor 21 puan olarak belirlenmiştir. Hareketi eksiksiz ve kompansasyon olmaksızın tamamlamaya 3 puan, kompansasyon mekanizmasının devreye girmesi durumda 2 ve hareketin talimat verildiği gibi tamamlanamadığı durumda 1 puan verilmiştir. Hareket gerçekleștirilirken ağrı bildirildiğinde sporculara 0 puan verilmiștir.

Toplam FMS skorları $\leq 14$ olan sporcular yaralanma açısından risk taşıdıkları şekilde tanımlanmıştır ve sol ve sağ tarafta farklı puan alan oyuncular asimetrik olarak kabul edilmiştir (Aka, Yılmaz, Aktuğ, Akarçeşme ve Altundağ, 2019; Altundağ, Soylu, Akarçeşme ve Yıldırım, 2019; Cook, Burton ve Hoogenboom, 2006a; Cook, Burton ve Hoogenboom, 2006b). 
Değerlendirmeler önden ve yandan olmak üzere iki farklı kamera ile kaydedilerek incelendikten sonra sporcuların FMS puanları hesaplanmıtır. Sporculardan FMS analizi öncesinde, test prosedürü gereği analiz sonuçlarını etkilememesi için, antrenmana başlamaması ve hiçbir germe egzersizi yapmaması istenmiştir. Her bir sporcunun FMS analizi ortalama 20 dakika sürmüş ve bütün sporcuların ölçümleri aynı gün içinde tamamlanmıştır.

\section{Egzersiz Programı}

Katılımcılara verilen egzersizler ana antrenman dışında ayrı bir çalışma programı olarak verilmiştir. Uygulanan düzeltici ve core egzersizler, 8 hafta boyunca haftada 3 gün antrenmanların ana bölümünü aksatmayacak şekilde, antrenman öncesinde uygulanmıştır.

Bu çalışmada FMS kurucuları tarafından belirlenen düzeltici egzersizler arasından, sporcuların genel olarak FMS alt parametrelerindeki yetersizlik durumlarına göre ve voleybola özgü temel hareket kalıplarını geliştirebileceği düşünülen hareketler seçilmiştir. Düzeltici egzersizler (foam roller, sopa, thera bant, pilates topu) 10 tekrar ve 2 set olacak şekilde uygulanmıștır. Core egzersizler ise katılımcılara 30 saniye boyunca ve 2 set olarak uygulanmiştır.

Tablo 1. Sporculara uygulanan egzersiz programı

\begin{tabular}{lll}
\hline Egzersiz Türü & & Süre-tekrar-set \\
\hline & Foam roller Hamstring & \\
Miyofasial & Foam roller Kuadriseps & 30 sn x 10 tekrar \\
Egzersizleri & Foam roller Addüktörler & \\
& Foam roller İliotibial bant & \\
& Foam roller Üst-Alt sirt & \multirow{2}{*}{10 tekrar x 2 set } \\
\hline Düzeltici & Dorsiflexion from Half Kneeling with Dowel \\
Egzersizler & Assisted Leg Lowering & \\
& Chop and lift from half kneeling & \\
& Single Leg Hip Hinge & \\
& Hard Roll & \\
& Quadruped rock back & $30 \mathrm{sn} \times 2$ set \\
Core & Plank prone hold & \\
Egzersizler & Side Prone hold & \\
& Glute Bridge & Plank with Arm extension \\
& Side Plank Rotation & \\
\hline
\end{tabular}


Resim 1. Foam roller ile yapılan düzeltici egzersizler (Miyofasial Gevşetme)
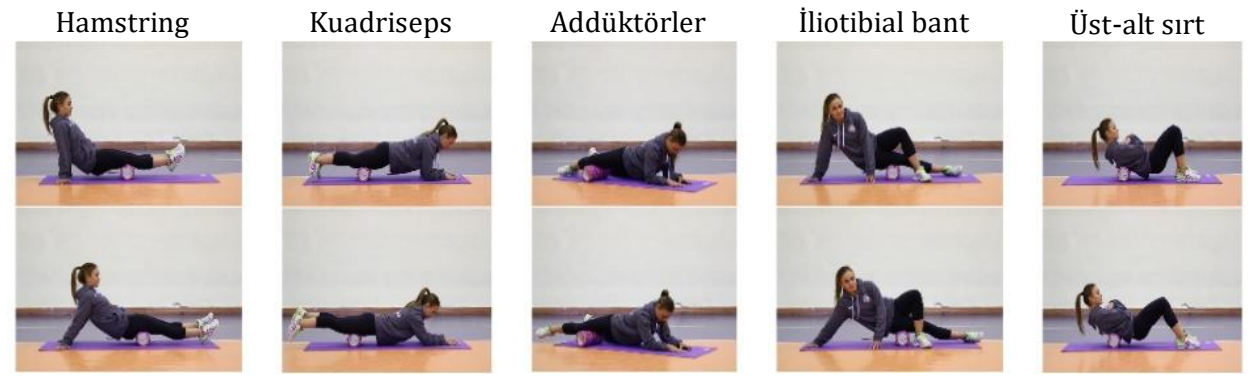

Resim 2. Düzeltici egzersizler
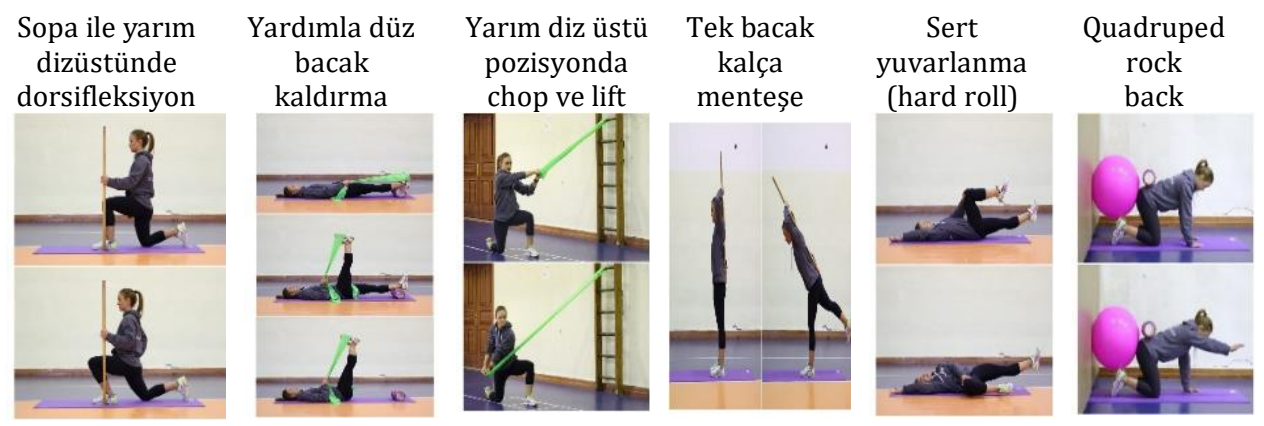

Resim 3. Core egzersizler
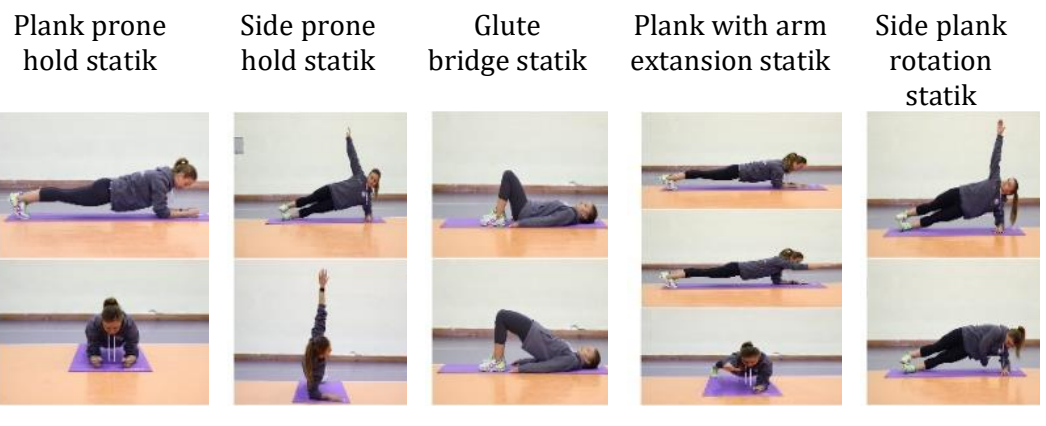
Glute bridge one leg statik

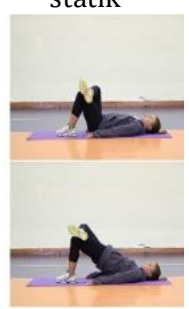

\section{Verilerin Analizi}

Çalışmada verilerin analizi için SPSS 24.0 paket programı (IBM, Chicago, IL, ABD) kullanılmıștır. Verilerin normallik dağılımı Shapiro Wilk testi ile sınanmıș, veriler normal dağılım göstermediğinden dolayı voleybolculara uygulanan egzersiz programı öncesi ve sonrası FMS alt testlerinin toplam puanları arasındaki farkın belirlenmesinde Wilcoxon İşaretli Sıralar Testi kullanılmıştır. Çalışmada anlamlılık düzeyi $\mathrm{p}<0,05$ olarak kabul edilmiştir. 


\section{Bulgular}

Tablo 2. Voleybolcuların demografik bilgileri

\begin{tabular}{lc}
\hline & $\overline{\boldsymbol{x}} \pm \mathbf{S s}$ \\
\hline Yaş (yıl) & $27,53 \pm 5,12$ \\
Boy uzunluğu (cm) & $181,00 \pm 9,86$ \\
Vücut ağırlı̆̆ı (kg) & $69,38 \pm 9,94$ \\
\hline
\end{tabular}

Tablo 3. Voleybolculara uygulanan düzeltici ve core egzersizler öncesi ve sonrası FMS test skorları

\begin{tabular}{|c|c|c|c|c|c|}
\hline Değişken & Eşli Grup & $\mathbf{n}$ & $\bar{x} \pm$ Ss & $\mathbf{Z}$ & $\mathbf{p}$ \\
\hline \multirow{2}{*}{ Derin çökme } & Ön Test & 13 & $1,61 \pm, 76$ & \multirow{2}{*}{$-1,890$} & \multirow{2}{*}{059} \\
\hline & Son Test & 13 & $2,00 \pm, 40$ & & \\
\hline \multirow{2}{*}{ Engel adımı } & Ön Test & 13 & $2,00 \pm, 00$ & \multirow{2}{*}{$-1,414$} & \multirow{2}{*}{ 157 } \\
\hline & Son Test & 13 & $2,15 \pm, 37$ & & \\
\hline \multirow{2}{*}{ İleriye düz çökme } & Ön Test & 13 & $1,84 \pm, 55$ & \multirow{2}{*}{$-1,890$} & \multirow{2}{*}{059} \\
\hline & Son Test & 13 & $2,23 \pm, 43$ & & \\
\hline \multirow{2}{*}{ Omuz hareketliliği } & Ön Test & 13 & $2,00 \pm 1,29$ & \multirow{2}{*}{$-2,041$} & \multirow{2}{*}{, $041^{*}$} \\
\hline & Son Test & 13 & $2,76 \pm, 43$ & & \\
\hline \multirow{2}{*}{ Aktif düz bacak kaldırma } & Ön Test & 13 & $2,92 \pm, 27$ & \multirow{2}{*}{$-1,000$} & \multirow{2}{*}{ 317 } \\
\hline & Son Test & 13 & $3,00 \pm, 00$ & & \\
\hline \multirow{2}{*}{ Şınav } & Ön Test & 13 & $2,38 \pm, 86$ & \multirow{2}{*}{$-1,342$} & \multirow{2}{*}{ 180 } \\
\hline & Son Test & 13 & $2,69 \pm, 48$ & & \\
\hline \multirow{2}{*}{ Gövde rotasyonu dengesi } & Ön Test & 13 & $1,23 \pm, 59$ & \multirow{2}{*}{$-3,31$} & \multirow{2}{*}{,001* } \\
\hline & Son Test & 13 & $2,07 \pm, 27$ & & \\
\hline \multirow{2}{*}{ FMS toplam skor } & Ön Test & 13 & $13,92 \pm 1,75$ & \multirow{2}{*}{$-3,19$} & \multirow{2}{*}{, $001^{*}$} \\
\hline & Son Test & 13 & $17,00 \pm 1,00$ & & \\
\hline
\end{tabular}

${ }^{*} \mathrm{p}<0,05$

Tablo 3 incelendiğinde voleybolcuların FMS alt testlerinden; omuz hareketliliği, gövde rotasyon dengesi ve FMS toplam skor değişkenlerinde ön test - son test arasında son test lehine anlamlı fark belirlenmiştir $(\mathrm{p}<0,05)$. Ayrıca FMS testinin diğer değişkenlerinde anlamlı fark belirlenmemesine rağmen son testte skorların geliştiği tespit edilmiştir.

\section{Tartışma ve Sonuç}

Fonksiyonel hareketler, kinetik zincir boyunca kontrolü sağlarken lokomotor, manipülatif ve stabilize edici hareketleri gerçekleştirme yeteneği olarak tanımlanır (Cook, Burton ve Hoogenboom, 2006a; Lockie ve diğerleri, 2015). Fonksiyonel bir hareket paterni doğru şekilde gerçekleştirilemediğinde bu hareketlerde işlevsel bozukluklar meydana gelebilir. Fonksiyonel hareket paternindeki işlevsizlik ise kas kuvvetindeki dengesizlik, nöromüsküler kontroldeki eksiklikler ya da asimetrilerden kaynaklanır ve bireyin fiziksel 
performansını tehlikeye atan bir duruma yol açabilir (Cook, Burton ve Hoogenboom 2006b; Cook, 2010; Cook, Burton, Hoogenboom ve Voight, 2014).

Yapılan bir çalışmada üst düzeyde aktif olan bireylerin basit hareketleri uygulayamadıklarında, bu hareketleri uygulama esnasında telafi edici hareket kalıplarını kullandıkları bildirilmiştir (Cook, Burton, Hoogenboom ve Voight, 2014). Bu nedenle sporcuların fonksiyonel hareketleri gerçekleştirme yeteneklerinin belirlenmesi, fiziksel performansın izlenmesinde ve yaralanma risklerinin tespit edilmesinde önceden yardım sağlayabilir. Bu bağlamda bu çalışmanın amacı, voleybolculara uygulanan core ve düzeltici egzersizlerin FMS test skorlarına etkisinin incelenmesidir.

Çalışmada voleybolculara uygulanan 8 haftalık core ve düzeltici egzersizler sonucunda sporcuların omuz hareketliliği ve gövde rotasyon dengesi puanlarının son testte anlamlı olarak arttığı tespit edilmiştir. Bu sonucun voleybolda tekrarlı bir şekilde uygulanan bazı temel tekniklerde sporcuların dominant tarafı baskın olarak kullanması ile vücutta oluşabilecek asimetriyi önleyebileceği düşünülmektedir. Sporcular özellikle servis ve smaç hareketlerinde, dominant taraf omuz eklemi ve harekete katılan diğer kas grupları tek yönlü olarak aşırı şekilde kullanılmaktadır. Omuz eklemlerinde, bir tarafta dış rotasyon meydana geldiği anda karşı omuz ekleminde iç rotasyon ve adduksiyon hareketinin olması gerektiği belirtilmektedir (Cook, Burton ve Hoogenboom, 2006b). Voleybolcuların fonksiyonel hareket paternlerinin gelişmesi tek yönlü olarak aşırı kullanım sonucu oluşabilecek kuvvet dengesizliklerine ve işlevsel bozulmalara karşı koruyucu strateji olabileceği düşünülmektedir. Çalışmada değerlendirilen diğer bir değişken olan FMS toplam skorlarının uygulanan core ve düzeltici egzersizler sonucunda son testte anlamlı olarak artış sağladığı belirlenmiş̦tir. Çalışmanın başında FMS toplam skorları yaralanma alt sınırının altında olduğu $(13,92)$, uygulanan core ve düzeltici egzersizler sonucunda ise kritik sınırın üstüne çıktığı $(17,00)$ tespit edilmiştir.

Yapılan çalışmalarda FMS toplam skorunda yaralanma kritik sınırının 14 puan olduğu ve bu puanın altında bir değer alan sporcularda yaralanma risklerinin yüksek olduğu belirtilmektedir (Güzel ve Kafa, 2017; Kiesel, Plisky ve Voight, 2007). Çalışma sonucunda FMS toplam puanındaki bu gelişme, sporcuların kuvvet asimetrisi, fonksiyonel hareketlerdeki işlevsizlik gibi nedenlerden dolayı yaralanma potansiyellerindeki azalma olarak düşünülebilir. Ayrıca bu sonuç fonksiyonel hareketlerin uygulanmasındaki verimliliği artırarak sporcularda performans gelişimini de sağlayabilir. Çalışmamızda FMS alt testlerindeki diğer skorların istatistiksel analiz sonuçlarına göre anlamlı fark olmamasına rağmen alt testlerin tamamında puan artışı olması dikkat çekmektedir.

Literatür incelendiğinde core ve düzeltici egzersizlerin birlikte uygulanarak fonksiyonel hareketlerin değerlendirildiği bir çalışma bulunmamaktadır. FMS test skorları ile core egzersizler veya düzeltici egzersizleri ayrı ayrı değerlendiren sınırlı sayıda çalışma bulunmaktadır. Aktuğ, Aka, Akarçeşme, Çelebi ve Altundağ (2019) kadın voleybolculara uygulanan 12 haftalık düzeltici egzersizlerin FMS test skorlarına etkisini araştırdığı çalışmalarında düzeltici egzersizlerin omuz hareketliliği ve FMS toplam puanlarını son testte anlamlı olarak artırdığını bulmuşlardır. Aktuğ, Aka, Akarçeşme, Çelebi ve Altundağ 
(2019) tarafından yapılan bir çalışma sonucunda FMS alt testlerindeki diğer skorlarında anlamlı fark olmamasına rağmen geliștiğini bildirmişlerdir. Kiesel, Plisky ve Butler (2011) profesyonel futbolculara yönelik olarak yapılan çalışmalarında, uygulanan düzeltici egzersiz programı sonucunda FMS toplam puanın geliștiğini saptamışlardır. Düzeltici egzersizlerin kas kuvvetine etkisine yönelik çalışmalarda da bir program dahilinde uygulandığında genel vücut kaslarını (Choi, Hur, Yang ve Park, 2005) ve sırt ekstansör kaslarının kuvvetini artırdığı belirtilmektedir (MajidiSiahtan ve Behbudi, 2015). Core egzersizlerin FMS test skorlarına etkisini inceleyen çalışmalara bakıldığında ise tek bir çalışmaya rastlanılmıştır. Kurt (2019) yaptığı çalışmasında 10-12 yaşları arasındaki yüzücülere uygulanan core egzersizler sonucunda FMS toplam puanlarının son testte anlamlı olarak arttı̆̆ını bulmuştur.

Ayrıca literatürde uygulanan core egzersizlerin ve yüzme antrenmanlarına ilaveten yapılan kuvvet egzersizlerinin temel motor becerileri ve yüzme performansını geliştirdiğini belirten çalışmalar da bulunmaktadır (Afyon ve Boyacı 2013; Bassett ve Leach, 2011). Sporcuların fonksiyonel hareket paternlerini farklı egzersiz programları uygulayarak geliştirmeye odaklanan çalışmalar da bulunmaktadır. Linek, Saulicz, Mysliwiec, Wójtowicz ve Wolny (2016) genç voleybolcularda stabilizasyon antrenmanlarının; Sprague, Mokha ve Gatens (2014) profesyonel voleybolcular ve futbolcularda müsabaka dönemi antrenmanlarının; Goss, Christopher, Faulk ve Moore (2009) tek bacak sıçrama, dikey sıçrama ve tekme atma egzersizlerinin FMS test skorlarını artırdığını bulmuşlardır.

Genel olarak yapılan çalışmalarda uygulanan farklı yaralanma önleme programları ile FMS puanlarının ortalama 4-6 hafta arasında geliștirilmeye bașlandığı belirtilmektedir (Butler ve diğerleri, 2013; Cowen, 2010; Goss, Christopher ve Faulk, 2009; Kiesel, Plisky ve Butler, 2011).

Yukarıda belirtilen araştırmalardaki kurguların çalışma sonuçlarıyla kısmen benzerlikler göstermesine rağmen bu çalışmalarda fonksiyonel hareket kalıplarının geliştirmesine odaklanarak farklı egzersizlerle FMS test puanlarının artırılmış olması, çalışma sonuçlarını destekler niteliktedir. Aktuğ, Aka, Akarçeşme, Çelebi ve Altundağ (2019) kadın voleybolculara 12 hafta uyguladığı düzeltici egzersizler ile FMS toplam puanını 12 haftada 2,5 puan artırırken çalışmamızda düzeltici egzersizler ile birlikte uygulanan core egzersizlerin 8 haftada FMS toplam puanını 3,08 puan gibi yüksek bir değerde artırması dikkat çekmektedir. Bu sonuç voleybol gibi haftalık antrenman ve maç yükünün fazla olduğu spor branşlarında, antrenmanlara ilave edilen düzeltici ve core egzersizlerin, sporcuların fonksiyonel hareket becerilerini kısa sürede geliştirerek yaralanma potansiyellerini azaltacağı ve fonksiyonel hareket verimliliğini artıracağ düşünülmektedir.

Sonuç olarak, voleybolculara 8 hafta boyunca uygulanan core ve düzeltici egzersizlerin omuz hareketliliği, rotasyon stabilitesi ve FMS toplam puanlarını son testte anlamlı olarak artırdığı; diğer alt testlerden alınan puanları ise anlamlı fark olmamasına 
rağmen geliştirdiği belirlenmiştir. Voleybolda sporculara uygulanan düzeltici ve core egzersizlerin, servis ve smaç gibi sık tekrarlanan temel tekniklerin aşırı kullanımının sonucunda oluşan asimetrilerin önlenmesine ve fonksiyonel hareket kalıplarının geliştirilmesine önemli bir katkı sağlayacağı düşünülmektedir. Voleybolda çalıştırıcıların sporcuların yaralanma risklerini azaltmak ve fonksiyonel hareket kalıplarını geliștirmek istediği durumlarda antrenman programlarına core ve düzeltici egzersizleri eklemeleri önerilebilir.

\section{Yazışma Adresi (Corresponding Address):}

Dr. Hasan AKA

Niğde Ömer Halisdemir Üniversitesi, Spor Bilimleri Fakültesi, NĭĞDE

ORCID: 0000-0003-0603-9478

E-posta: hasanaka06@gmail.com 


\section{Kaynaklar}

1. Afyon, Y. A. ve Boyacı, A. (2013). Investigation of the effects by compositely edited coreplyometric exercises in sedentary man on some physical and motoric parameters. International Journal of Academic Research, 5(3), 256-261.

2. Aka, H., Yilmaz, G., Aktug, Z. B., Akarçesme, C. ve Altundag, E. (2019). The comparison of the functional movement screen test results of volleyball national team players in different countries. Journal of Education and Learning, 8(1), 138-142.

3. Aktuğ, Z. B., Aka, H., Akarçeşme, C., Çelebi, M. M. ve Altundağ, E. (2019). Elit kadın voleybolcularda düzeltici egzersizlerin fonksiyonel hareket taraması test sonuçlarına etkileri. Spor Hekimliği Dergisi, 54(4), 233-241.

4. Altundağ, E., Soylu, C.., Akarçeşme, C. ve Yıldırım, N. Ü. (2019). The relationship between isokinetic shoulder muscle strength at diagonal pattern, serve speed and functional movement screen (FMSTM ${ }^{\top}$ ) in female volleyball athletes. International Journal of Applied Exercise Physiology, 8(3.1), 126-135.

5. Aslan, C. S., Koç, H. ve Karakollukçu, M. (2015). Voleybol 1. liginde oynayan erkek sporcuların seçilmiş fiziksel, fizyolojik ve motorik özelliklerinin belirlenmesi. İnönü Üniversitesi Beden Eğitimi ve Spor Bilimleri Dergisi, 2(3), 1-13.

6. Atan, T. (2013). Effect of jogging and core training after supramaximal exercise on recovery. Turkish Journal of Sport and Exercise, 15(1), 73-77.

7. Axel, T. A. (2013). The effects of a core strength training program on field testing performance out comes in junior elite surf athletes (Yüksek Lisans Tezi). California State University, Long Beach.

8. Bassett, S. H. ve Leach, L. L. (2011). The effect of an eight-week training programme on core stability in junior female elite gymnasts. African Journal for Physical, Health Education, Recreation and Dance, 17(3), 9-19.

9. Behm, D. G., Drinkwater, E. J., Willardson, J. M. ve Cowley, P. M. (2010). The use of instability to train the core musculature. Applied Physiology, Nutrition, and Metabolism, 35(1), 91-108.

10. Butler, R. J., Contreras, M., Burton, L. C., Plisky, P. J., Goode, A. ve Kiesel, K. (2013). Modifiable risk factors predict injuries in firefighters during training academies. Work, 46(1), 11-17.

11. Choi, E. H., Hur, J. K., Yang, J. I. ve Park, D. S. (2005). The effect of thoracic exercise program on thoracic pain, kyphosis, and spinal mobility. Arch Phys Med Rehabil, 86(9), e23.

12. Chorba, R. S, Chorba, D. J, Bouillon, L. E., Corey A. Overmyer, P. T., James A. ve Landis, M. D. (2010). Use of a functional movement screening tool to determine injury risk in female collegiate athletes. $N$ Am J Sports Phys Ther (NAJSPT), 5(2), 47-54.

13. Cook, G., Burton, L. ve Hoogenboom, B. (2006a). Pre-participation screening: the use of fundamental movements as an assessment of function - part 1. N Am J Sports Phys Ther, 1(2), 62-72.

14. Cook, G, Burton, L. ve Hoogenboom, B. (2006b). Pre-participation screening: the use of fundamental movements as an assessment of function - part 2. N Am J Sports Phys Ther, 1(3), $132-9$.

15. Cook, G. (2010). Movement: Functional Movement Systems. Screening-AssessmentCorrective Strategies. On target Publications: Santa Cruz, California, 408.

16. Cook, G., Burton, L., Hoogenboom, B. J. ve Voight, M. (2014). Functional movement screening: the use of fundamental movements as an assessment of function - part 1. Int J Sports Phys Ther, 9(3), 396-409. 
17. Cowen, V. S. (2010). Functional fitness improvements after a worksite-based yoga initiative. J Bodyw Mov Ther, 14(1), 50-54.

18. Fig, G. (2005). Strength training for swimmers: training the core. Strength \& Conditioning Journal, 27(2), 40-42.

19. FMS $^{\mathrm{TM}}$. Updates to the Functional Movement Screen: An Insider Interview with FMS ${ }^{\mathrm{TM}}$ Co-founders: FMS 2020 [Available from:

https://www.functionalmovement.com/articles/908/updates_to_the_functional_moveme nt_screen_an_insider_interview_with_FMS ${ }^{\mathrm{TM}}$ _co-founders.

20. Goss, D. L, Christopher, G. E, Faulk, R. T. ve Moore, J. (2009). Functional training program bridges rehabilitation and return to duty. J Spec Oper Med, 9(2), 29-48.

21. Güzel, N. ve Kafa, N. (2017). Sporcu sağlı̆̆ı. Ankara: Sözkesen Matbaacılık.

22. Hibbs, A. E, Thompson, K. G, French, D., Wrigley, A. ve Spears, I. (2008). Optimizing performance by improving core stability and core strength. Sports medicine, 38(12), 9951008.

23. Kiesel, K., Plisky, P. J. ve Voight, M. L. (2007). Can serious injury in professional football be predicted by a preseason functional movement screen? N Am J Sports Phys Ther (NAJSPT), 2(3), 147-58.

24. Kiesel, K., Plisky, P. ve Butler, R. (2011). Functional movement test scores improve following a standardized off-season intervention program in professional football players. Scand J. Med. Sci Sports, 21, 287-292.

25. Kiesel, K., Plisky, P. ve Kersey, P. (2008). Functional movement test score as a predictor of time- loss during a professional football team's pre-season. American College of Sports Medicine Annual Conference, Indianapolis.

26. Kraus, K., Schütz, E., Taylor, W. R. ve Doyscher, R. (2014). Efficacy of the functional movement screen: a review. J. Strength Cond. Res, 28, 3571-3584.

27. Kurt, S. (2019). Yüzücülere uygulanan core egzersizlerinin fonksiyonel hareket tarama skorları ve sportif performans üzerine etkisi (Yüksek Lisans Tezi). Niğde Ömer Halisdemir Üniversitesi, Sosyal Bilimler Enstitüsü, Niğde.

28. Linek, P., Saulicz, E., Mysliwiec, A., Wójtowicz, M. ve Wolny, T. (2016). The effect of specific sling exercises on the fonctional movement screen in adolescent volleyball players: A preliminary study. J Hum Kinet, 15(54), 83-90.

29. Lockie, R., Schultz, A., Callaghan, S., Jordan, C., Luczo, T. ve Jeffriess, M. (2015). A preliminary investigation into the relationship between functional movement screen scores and athletic physical performance in female team sport athletes. Biol Sport, 32(1), 41-51.

30. MajidiSiahtan, S. ve Behbudi, L. (2015). The impact of 8-week selected pilates exercises on lordosis correction and BMI in female teens aged 15-18. Biological Forum International Journal, 7(1), 1267-71.

31. Minick, K. I., Kiesel, K. B., Burton, L., Taylor, A., Plisky, P. ve Butler, R. J. (2010). Interrater reliability of the functional movement screen. J. Strength Cond. Res, 24, 479-486.

32. Mokha, M., Sprague, P. A. ve Gatens, D. R. (2016). Predicting musculoskeletal injury in national collegiate athletic association division II athletes from asymmetries and individualtest versus composite functional movement screen scores. J Athl Train, 51(4), 276-82.

33. Onate, J. A., Dewey, T., Kollock, R. O., Thomas, K. S., Van Lunen, B. L., DeMaio, M. ve Ringleb, S. I. (2012). Real-time intersession and interrater reliability of the functional movement screen. J. Strength Cond. Res, 26(2), 408-415.

34. Samson, K. M. (2005). The effects of a five-week core stabilization-training program on dynamic balance in tennis athletes (Yüksek Lisans Tezi). West Virginia University, Morgantown. 
35. Sprague, P. A., Mokha, G. M. ve Gatens, D. R. (2014). Changes in functional movement screen scores over a season in collegiate soccer and volleyball athletes. J Strength Cond Res, 28(11), 3155-3163.

36. Willardson, J. M (Ed). (2014). Developing the core. Human Kinetics: United States. 